Paideusis

\title{
Libri ad Nauseam: The Critical Thinking Textbook Glut
}

\section{Benjamin Hamby}

Volume 21, numéro 1, 2013

Contemplative Practice, Education, and Socio-Political

Transformation (Part Two)

URI : https://id.erudit.org/iderudit/1071573ar

DOI : https://doi.org/10.7202/1071573ar

Aller au sommaire du numéro

\section{Éditeur(s)}

Canadian Philosophy of Education Society

ISSN

0838-4517 (imprimé)

1916-0348 (numérique)

Découvrir la revue

Citer cet article

Hamby, B. (2013). Libri ad Nauseam: The Critical Thinking Textbook Glut. Paideusis, 21(1), 39-48. https://doi.org/10.7202/1071573ar

\section{Résumé de l'article}

Critical thinking instructors are faced with an overwhelming number of textbooks to choose from for their courses. Many of these texts do not reflect an awareness of current scholarship in critical thinking and informal logic. I argue that instructors should only adopt textbooks that reflect a sound theoretical understanding of the topic by acknowledging the central role of critical thinking dispositions, offering a more nuanced approach to the teaching of fallacies and of inference, stressing dialectic and argument revision, focusing on the analysis and evaluation of real arguments, and broadening the scope of critical thinking beyond argument analysis and evaluation. To support instructors in this regard, I critique one popular textbook now in its sixth edition that does not satisfy many of these criteria, Munson and Black (2012), and applaud one new textbook that I find does succeed on many of these fronts, Bailin and Battersby (2010).
Ce document est protégé par la loi sur le droit d'auteur. L'utilisation des services d'Érudit (y compris la reproduction) est assujettie à sa politique d'utilisation que vous pouvez consulter en ligne.

https://apropos.erudit.org/fr/usagers/politique-dutilisation/ 
Paideusis, Volume 21 (2013), No. 1, pp. 39-48.

\title{
Libri ad Nauseam: The Critical Thinking Textbook Glut
}

\author{
BENJAMIN HAMBY \\ McMaster University
}

Critical thinking instructors are faced with an overwhelming number of textbooks to choose from for their courses. Many of these texts do not reflect an awareness of current scholarship in critical thinking and informal logic. I argue that instructors should only adopt textbooks that reflect a sound theoretical understanding of the topic by acknowledging the central role of critical thinking dispositions, offering a more nuanced approach to the teaching of fallacies and of inference, stressing dialectic and argument revision, focusing on the analysis and evaluation of real arguments, and broadening the scope of critical thinking beyond argument analysis and evaluation. To support instructors in this regard, I critique one popular textbook now in its sixth edition that does not satisfy many of these criteria, Munson and Black (2012), and applaud one new textbook that I find does succeed on many of these fronts, Bailin and Battersby (2010).

\section{Introduction}

[Critical thinking] courses tend to be taught by graduate students or junior faculty who . . get little to no exposure to the informal logic literature in their training in philosophy. Their sole exposure is to similar courses they took as undergraduates and to the deductive and inductive logic courses they have taken as seniors or graduate students. When they come to choose a textbook, what they want is one with whose contents they are familiar, which will be one that embodies all the mistakes and misrepresentations that they have learned. (Blair 2006, p. 282)

The burgeoning of textbook choices accompanying the popularity of standalone courses that are billed explicitly as "critical thinking", "critical reasoning", or what Johnson and Blair (2009) call a "call it what you will' course" (p. 2), makes it a significant challenge for instructors to choose a textbook. Matters are made more difficult when one actually begins to examine these products. For then one discovers how alike many of them are, typically equating critical thinking with argumentation, beginning with an introductory chapter on the nature of argument, and moving on to brief treatments of deductive reasoning, propositional logic, and probabilistic reasoning. Many books go on to present a chapter each on informal fallacies, arguments by analogy, causal arguments, and language and definition, often concluding with a closing chapter or appendix on how to compose an argumentative essay. This is the well worn territory of critical thinking pedagogy

(C) Copyright 2013. The author, Benjamin Hamby, assigns to Paideusis the right of first publication and educational and non-profit institutions a non-exclusive license to use this document for personal use and in courses of instruction provided that the article is used in full and this copyright statement is reproduced. Any other usage is probibited without the express permission of the author. 
reflected in many textbook approaches: a "dog's breakfast" $(2009$, p. 2) of content that is not up to date with the current literature in critical thinking and informal logic. ${ }^{1}$

Many textbooks exhibit a variety of flaws and limitations as a result. For example, they may fail

- to recognize the central role of proper dispositions in critical thinking, though in general terms this is a near-unanimous point of agreement among critical thinking theorists (Facione, 1990); ${ }^{2}$

- to reflect a nuanced approach to the teaching of fallacies beyond an adversarial and taxonomic labeling approach (Hundleby, 2010);

- to show an awareness of the problem of characterizing the deductive-inductive distinction (Blair, 2006);

- to stress dialectic, dialogue, or argument revision (Blair, 2006); and/or

- to focus on the analysis and evaluation of real arguments that have been or could plausibly be used in practice (Hamby, 2012).

Furthermore, textbooks commonly equate reasoning and argument analysis with critical thinking, but this is a common assumption that has been discredited (Govier, 1989). Finally, even when textbooks themselves are careful not to equate critical thinking with argument analysis and evaluation, critical thinking instructors continue to adopt such textbooks assuming that teaching argument analysis is sufficient to teach critical thinking. Faced with products that ignore theoretical concerns such as these, examiners who are largely ignorant of the relevant scholarly literature will not realize how problematic such approaches are for a critical thinking class.

Those of us who care about critical thinking should see a problem: textbook authors are writing introductory treatments of critical thinking that are often doing little more than recasting older textbook approaches, and instructors are adopting these textbooks, comforted by their familiarity, but ignorant of their pedigree. In this paper, I will highlight some important (though non-exhaustive) criteria by which to judge a critical thinking textbook, pointing out the need for critical thinking instructors and authors to be aware of how their pedagogical practice aligns (or does not align) with current scholarship that underwrites these criteria. I will then compare and contrast two textbooks, one of which, Bailin and Battersby (2010), I find meets many of these criteria, and one of which, Munson and Black (2012), I find does not.

\section{The Scholarly Call to Improve Critical Thinking Theory and Pedagogy}

A defensible conception of critical thinking should go hand in hand with a defensible critical thinking pedagogy. So, twenty years ago, in the face of the ever-increasing popularity of the educational ideal of critical thinking and a corresponding proliferation of conceptualizations of it, Johnson (1992) called for a moratorium on new definitions, proposing that none be stipulated until the major extant ones had been

\footnotetext{
${ }^{1}$ Scholarship that is found in abundance in relevant journals, for instance, such as Informal Logic, Argumentation, Cogency, Inquiry: Critical Thinking across the Disciplines, and Teaching Philosophy, to name a few. See Johnson and Blair (2009). See also Weinstein (1995) for an important critique from within the critical thinking community of the way critical thinking is usually conceived and taught, wherein he offers an alternative that "requires a radical shift in the self-conception of college faculty" (p. 37).

2 To my knowledge there is only one critical thinking theorist who argues against this consensus regarding critical thinking dispositions: Missimer (1990, 1995). However, her "skills-alone" position, denying that critical thinking involves character, is unconvincing. Support for this point is provided by Siegel (1990).
} 
thoroughly critiqued and improved upon. ${ }^{3}$ By implication, the new definitions that would be offered when that time came would need to show how their preferred meaning of critical thinking differed from other cognate terms such as reasoning, rationality, and problem-solving (what Johnson called "the network problem"); they would need to show in what sense the word "critical" operated in their definition (avoiding a connotation with a purely negative meaning of the word); they would need to be a part of a developed theory of critical thinking (as opposed to a standalone definition found in a textbook); and they would need to help support assessments of critical thinking (as opposed to not indicating any way to measure for critical thinking).

Unfortunately, it seems Johnson's plea has gone unheeded: new definitions have multiplied, mostly not in the form of developed theories, but in the form of introductory textbook approaches that do indeed assume an a priori connection to other cognate terms such as "reasoning", that do not yield assessment tools, and that do not make sufficiently clear why they employ the term "critical". We remain stuck in a rut of textbook conceptions of critical thinking that have not addressed Johnson's theoretical questions, and that have therefore not improved our pedagogy beyond older approaches. For students who are not exposed to the extant rival conceptions of critical thinking, each with their own justification, this is a missed opportunity: with more explicit attention paid to the very concept of critical thinking in a textbook or course, students would have the opportunity to think critically in practice about the concept of critical thinking.

To Johnson's critique we can add the critical comments of Hundleby (2010), who has recently questioned the authority of the traditional way the fallacies are classified and taught to students, condemning that approach as being based on "a corrupt epistemic authority that makes the common practices of fallacy allegation authoritarian" (p. 280). Rather than being justifiably authoritative, fallacy theory via the common textbook approach is flawed and perpetuates a problematic understanding of fallacious argument. Hundleby goes further, though, and argues that "the authority of the popular pedagogical treatments is illegitimate because of the priority it gives to the Adversary Method" (p. 299), thus encouraging students to knock down arguments without constructively revising them in plausible ways. So our pedagogical approach is flawed in a way that perpetuates intellectual and epistemological paradigms that marginalize cooperation and argument revision in favor of argumentative competition and destruction.

Hundleby's treatment is important because her review of 24 textbooks highlights the common practice of textbook authors ignoring the theoretical concerns of argumentation theory. She observes that, while "[r] eviewing the status of particular fallacies is a large component of fallacies scholarship . . this sort of epistemological review remains unheeded when authority is granted to publish textbooks or teach courses, as we see from the outdatedness of typical instruction methods"(p. 300). If Hundleby is right, then authors and instructors, in addition to publishers, bear at least part of the responsibility for not informing themselves of the relevant scholarship that should inform their pedagogy.

This diagnosis of a widespread ignorance of fallacy scholarship in critical thinking texts is corroborated by Blair (2006), whose critique of the traditional pedagogical treatment of fallacies is worth quoting at length:

The views that the concept of fallacy is unproblematic, that the "formal vs. informal fallacy" distinction is illuminating, that Aristotle's distinction between fallacies dependent on language and those independent of language is unproblematic, and especially that there are easilyidentifiable and classifiable lists of logically fallacious argument or reasoning types that are readily teachable — that is, can be learned with benefit to the student's reasoning-in a one or two week segment of a course, are nothing short of intellectually irresponsible under the conditions of theoretical development of fallacy theory in the past 30 years. (p. 264)

This intellectual irresponsibility is evinced in textbook approaches that have a short, lone chapter on fallacies, encouraging instructors to write syllabi that cover that material as quickly as its brevity allows: an approach that is very common. It is time instructors recognized, and the textbooks they adopt reflected, the

\footnotetext{
${ }^{3}$ Those major definitions Johnson dubbed the "group of five": Ennis (1989), Paul (1989), Lipmann (1988), Siegel (1988), and McPeck (1981).
} 
fact that there is a great deal of scholarship regarding the fallacies in particular, and argumentation more generally. Should every critical thinking instructor become an expert in fallacy scholarship or theory of argumentation before teaching a critical thinking course? No, but the same old pedagogical approach that perpetuates a traditional understanding of both, unaware of contemporary thinking, is doing our students a disservice. This is especially the case with fallacies, a subject area that, if it is not covered thoroughly, should not perhaps be covered at all (cf. Hundleby (2010)). Finally, Blair does not restrict himself to critiquing the way fallacies are typically introduced to students. In fact, he notes eight different ways that informal logic scholarship should influence philosophy instruction, among these being a recognition of the plurality of ways that inferences can be made other than deductively or inductively, orienting argument analysis towards the dialectical nature of argumentation, and examining the different ways of conceptualizing argument (pp. 260270). In addition, with regard to the supposed equivalence of argument analysis with critical thinking, he says:

Once the range of types of objects of critical assessment is made explicit, it becomes evident that the logic of arguments, formal or informal, hardly exhausts the criteria, procedures and strategies needed for informed critical thinking, and the assumption that a logic course, whether it includes just instruction in the rules of valid deduction or broader criteria for assessing arguments, can suffice as a critical thinking course, is exposed as narrow and naïve. (p. 265)

These, and the other observations Blair makes regarding the mostly absent influence of informal logic scholarship on critical thinking and basic reasoning instruction within philosophy departments, are serious critiques from an authoritative scholar in the informal logic community, and they should make any pedagogue and their department administrator pause.

Along these lines, Govier (1989) also thoroughly discounts the tendency simply to equate argument analysis and evaluation with critical thinking. ${ }^{4}$ While she says, quite rightly, that "[i]t is obvious that being able to analyze critically natural arguments is at least one important component in being able to think critically," she also goes on to say that the "conflation of critical thinking and argument analysis is a mistake" (p. 117). Alas, it seems this conclusion has been largely overlooked for the last 23 years. Textbooks-and, by implication, syllabi-tend not to differentiate between thinking critically and argumentation, nor between argumentation and reasoning (p. 117). Students instead are taught to equate all three, but engaging in argumentation is only one kind of reasoning, and as Govier rightly points out: "attending [only] to arguments may cause us to neglect other aspects of discourse which deserve our critical attention," such as questionable hypotheses that are assumed, language that is emotionally charged, and alternative perspectives that might be ignored (p. 118). To focus exclusively on written or spoken arguments in a critical thinking course is therefore a mistake, because "[w]ords and arguments are not the only things which merit our critical attention" (p. 118). This is not a call to ignore instruction in argument analysis and evaluation, but a call to acknowledge that such instruction is not sufficient to teach critical thinking.

Finally, I have argued elsewhere (Hamby, 2012) that real arguments are the arguments that should be studied in a critical thinking class: arguments that, following Govier (2009) have "prospective use" as tools of rational persuasion, or for other uses in the context of deciding what to believe or do. If the arguments taken up in a critical thinking class are not real arguments, then the relevance of material studied in such a course is threatened. Students need to be exposed to arguments that they might actually encounter in their lives as believers and doers in order for them to take seriously the hard work involved in going through the challenging process of thinking critically.

Critical thinking instructors and authors of critical thinking textbooks should be aware of such perspectives, which have received much critical attention, and this awareness should inform the course design of their critical thinking classes and the books that they write and adopt for those courses. Does a textbook equate the analysis and evaluation of arguments with critical thinking? Does a textbook treat the detection of fallacies as a destructive tool for argument evaluation? Does a textbook fail to acknowledge the role of

\footnotetext{
${ }^{4}$ This even while she has an excellent and very popular textbook on argument now published in its latest "Enhanced"

$7^{\text {th }}$ edition Govier (2013), which many instructors adopt for their critical thinking classes.
} 
critical thinking dispositions? Does a textbook treat the deductive/inductive distinction without due care? Does a textbook use examples of argument that are unrealistic, or overly artificial in their articulation such that they have no prospective use in real-life argumentation? If the answer is "yes" to all or to most of these questions, then such a textbook should be seen as being less than ideal for a critical thinking class. ${ }^{5}$

\section{One Problematic Critical Thinking Textbook}

One case in point is Munson and Black's The Elements of Reasoning, 6th Edition (2012), a popular book with widespread use in introductory philosophy and reasoning courses. An Internet search of syllabi that list this book reveals that some instructors adopt it as a textbook for their critical thinking courses in particular. I have chosen to exhibit this book because I think it represents a common format for textbooks that many instructors are apt to adopt for their critical thinking course. ${ }^{6}$ I have also chosen this book because, despite some improvements in its latest edition, despite its popularity, and despite its common approach, it has a number of shortcomings when measured against the criteria that I have summarized above. In my judgment, these shortcomings make their book one that should not be adopted for a critical thinking course.

Contrary to what Blair and Govier recommend, for instance, the text suggests that reasoning is equivalent to "the rational process of analyzing, defending, and evaluating claims" (p. vii). In other words, the authors characterize reasoning as the process of argument analysis and evaluation, whereby claims are examined according to the reasons that are offered to support them. This is problematic, because one could reason about something without doing argument analysis and evaluation, such as when one makes a snap judgment, when one decides what route to take to get to a destination, or when one wonders about what happens after we die. These are all things we do through reasoning, but we are not always arguing when we reason about them. Furthermore, while the words "critical thinking" appear in the body of the text only once (p. 30), even if we take the book as not strictly speaking being intended by the authors as a critical thinking textbook, instructors who adopt it are surely treating it as such when they require it as their primary (or their only) book for their critical thinking course. I would argue that, because critical thinking is more than argument analysis and evaluation, this textbook should not be treated as a critical thinking textbook. An additional concern is the book's length. The authors themselves do not even call their book a "textbook" but rather refer to it as a "handbook" (p. ix). While its modest length, its comparatively less expensive price, and its standard format make it attractive to some, its adoption as the primary or only textbook in a critical thinking class is problematic just because it is so concise. By making these initial comments I should not be interpreted as implying that the book should never be adopted, only that to adopt it as a primary textbook for a term-length course in critical thinking is unattractive because it is not technically a critical thinking textbook, and because it is not technically a textbook.

These are not the only shortcomings of Munson and Black's book when considered as a potential textbook for a critical thinking or other philosophy course. Their brief chapter on fallacies exhibits a number of flaws. First, they quite simplistically and over-broadly call a fallacy "any error in reasoning" (p. 124), even though it is traditionally acknowledged that fallacies often occur specifically in real arguments, not just in any kind of reasoning (cf. Hitchcock, 2007), that they are not just errors or mistakes, but mistakes that "people are taken in by" (2007 p. 188), and that they are mistakes that are commonly committed (cf. Govier, 1995). Though this is a traditional conception, other nuanced perspectives are extant as well. Thus, glossing the concept of fallacy too simplistically, without reference to its complicated and contentious nature, is a mistake.

The authors go on to offer an encyclopedic treatment of fallacies according to a taxonomic approach. They divide their taxonomy into two major categories: "Fallacies in Supporting a Claim" (pp. 124132) such as ad ignorantium and ad populum and "Fallacies of Criticism and Response" (pp. 132-138) such as ad hominem; the fallacies that they place in these categories thus have mostly traditional labels that the authors

\footnotetext{
${ }^{5}$ I leave it to instructors to make a judgment as to mixed cases, where a textbook fails to meet some but not all of these criteria.

${ }^{6}$ A few books reviewed by Hundleby (2010), for instance, have much the same format and content, e.g. Rudinow, Barry, and Letteri (2008), Moore and Parker (2007), Vaughn and MacDonald (2008), and Dayton (2010).
} 
give traditional summaries, and are illustrated by many examples that are short, contrived, and do not stress context. For example, readers are prompted to spot the fallacies of criticism (p. 143). Question number 4 on this page gives the following passage: "The president of Entron is as bankrupt morally as his company is financially." One assumes that the authors consider this an abusive ad hominem attack. But some context might easily render such a statement legitimate, for instance if the morality of the president of Entron were being questioned.

In addition, the exercises for the chapter are divided into sections, one of which problematically prompts the reader to identify fallacies "most [of which] are fallacies of relevance. . or inadequate evidence" (p. 140), and in another section, to identify fallacies "of illegitimate assumption" (p. 141). In this way, the student is artificially prompted to label fallacies according to the authors' taxonomy, and the authors unrealistically indicate which taxonomy to place the passage in prior to assessment by the reader. This is unrealistic, because in practice the arguments a person hears are not pre-determined to contain a fallacy, nor if they are fallacious is it always clear what broad category of fallacy they fall under. Such an approach perpetuates an adversarial model of fallacy instruction which begins and ends at identification, giving no credence to how identifying fallacies can be the first step of a constructive even if critical dialectic, as opposed to the first and last step of a destructive critique.

Finally, the exercises are almost all manufactured, only 5 out of 46 of them coming from citable sources (pp. 138-145). This tailoring of artificial examples of fallacies to fit the taxonomy introduced in the text does not realistically foster a student's ability to identify and properly respond to fallacies in practice. Instead, it encourages a rote understanding of label-ready fallacies, ironically working against what the authors have in mind when they say that "[a] label, after all, can never be a substitute for a critical assessment" (p. 124).

A positive aspect of this chapter, but one the authors only scratch the surface of, is the recognition that some fallacies are instances of schemes that are often not fallacious. The authors call this "good reasoning that looks bad" (pp. 125-126), but unfortunately they only provide this nuanced perspective for one fallacy: the appeal to ignorance. Their treatment would have been much improved had they taken a similar approach to the remaining fallacies they introduce, where they could have done so, such as showcasing legitimate ethotic schemes that do not count as fallacious ad hominem attacks. ${ }^{7}$

Another somewhat redeeming aspect of their treatment of fallacies, one which represents an improvement over previous editions, is their acknowledgement in the exercises section that "[i]t is more important to be able to recognize a bad argument and say what is wrong with it than to be able to put a label on it" (p. 138). Munson and Black's book deserves a nod for acknowledging this important point. However, the book only prompts readers to give explanations for their answers to the first two ("PhilosophicalPractical") exercises, and in the remaining ("Technical") exercises, only prompts explanations for fallacies where the reader is uncertain of the label. But whether uncertain of the label or not, students should always be encouraged to provide reasons for why they think a particular passage is or is not fallacious. A related improvement in their latest edition is that the answers in the back of the book do have explanations for why the authors give the answers that they give, but it is a minor shortcoming of the exercises section that readers are not prompted to provide an explanation for each answer.

In addition, while 3 of the 44 technical exercises in this chapter are written in dialogue form, indicating that the allegation of a fallacy occurs in an ongoing dialectic, often in a social context, more could be so written. On a related point, nowhere in the chapter do the authors indicate a strategy for argument revision and repair, neglecting to encourage students to think of ways that the argument in question could be improved such that it would successfully avoid the label of fallacy. This again perpetuates an adversarial way of looking at the fallacies, deemphasizing constructive critique while emphasizing destructive monological criticism. It is more important to recognize problematic aspects of an argument that make it fallacious, and what might make it not fallacious, than it is simply to put a label on it, even if one goes on to say why the label is

\footnotetext{
${ }^{7}$ Cf. Groarke \& Tindale (2012), pp. 320-324, where they refer to legitimate "ethotic" arguments, or those that "explicitly address the character of the arguer" (p. 307). See also Hitchcock (2007) who argues that attacking the ethos of an arguer in an abusive ad hominem is not a fallacy because such attacks are often legitimate, and when they are not, constitute an "objectionable diversionary tactic" (p. 199), not a mistake of reasoning.
} 
deserved. This is because our critical thinking is often not merely a solo intellectual exercise, conducted only in our heads, but is conducted in public and with other people, often to reach consensus, foster understanding, and make collective decisions. One next step in the practice of fallacy identification should therefore be an attempt to make the fallacious argument better.

So, despite some positive improvements from previous editions, Munson and Black's chapter on fallacies still suffers from every criterion that Hundleby (2010) says a quality treatment of fallacies should avoid: no discussion of argument repair; short or decontextualized, manufactured examples; and a taxonomic labeling approach (pp. 286-289). I would add Munson and Black's book to Hundleby's list of 24 books that fail on these fronts.

There are additional reasons to decide not to adopt Munson and Black's book for a critical thinking course, even beyond those already mentioned: it does not stress the dispositions necessary for a person to be a critical thinker, such as open-mindedness, intellectual honesty, courage, and a commitment to reason. This is a regrettable omission because these are the kinds of intellectual virtues that scholars have agreed are constituent aspects of critical thinkers, ensuring that those who are developing the intellectual skills of critical thinking will put them to appropriate use. ${ }^{8}$ The contrary arguments of Missimer (1990, 1995) notwithstanding, the panoply of critical thinking dispositions, character traits, and attitudes - what Siegel (1988) has called following Passmore (1967) "the critical spirit" - are certainly an important part of the practice of critical thinking to which students should be introduced. Such an emphasis would also work to mitigate the adversarial approach that is instilled in students when they are told, as the publishers apparently tell them regarding this book, that it will help them learn "how to analyze and then destroy an argument" (Publisher's comments, n.d.). In light of its neglect of critical thinking dispositions and its other shortcomings discussed above, I think it is legitimate to conclude that there are more attractive candidates for textbook adoption in a critical thinking course.

\section{One Recommended Critical Thinking Textbook}

Bailin and Battersby (2010) have recently published a book featuring a unique approach to critical thinking that succeeds where many other textbooks fail. While there is room for improvement in future editions, their text is a superior product: an inquiry approach to critical thinking stressing dialectical context, backed up by their own scholarly efforts, and exhibiting a familiarity with informal logic and critical thinking scholarship generally. ${ }^{9}$ In every respect that I have enumerated above, where Munson and Black's book falls short, Balin and Battersby's book succeeds.

First, the authors do not equate critical thinking with reasoning or argument analysis, though their book does include many chapters on argumentation and argument analysis. Second, it is truly argumentation and not simply argument to which students are introduced. In other words, argument is treated in the "broad sense" as it is uttered by people in context-specific situations of dialectic and dialogue (Cf. Woods, Irvine, and Walton, 2003, and Blair, 2006). The authors stress that critical thinking is a kind of inquiry: a process of "carefully examining an issue in order to come to a reasoned judgment" (Bailin and Battersby, 2010, p. 4) that often occurs in social interaction. Casting critical thinking this way implies that the process of critical thinking involves more than the parsing of arguments, stressing context and constructive analysis, not just isolated critique. It also stresses the examination and evaluation of alternative arguments, so that a monological critique of any one argument is never enough to count as critical thinking. This makes their approach much more applicable to real life situations where arguments are used in efforts to persuade or justify or for other uses in the context of making socially situated judgments concerning controversial questions.

\footnotetext{
${ }^{8}$ Cf. Dewey (1910), Glaser (1941), Passmore (1967), Scheffler (1986), Siegel (1988), Millman (1988), Paul (1989), Ennis (1996), Bailin, et al. (1999a, 1999b), Facione (2000), and Battaly (2006, 2007).

${ }^{9}$ One way their book could be improved in future editions is to provide citations throughout the text that reference the scholarly literature that informs their approach.
} 
Second, their treatment of fallacies is not limited to a chapter that merely breaks down errors in reasoning in a taxonomic manner. Instead, they cover fallacies throughout the textbook, notably in the context of different kinds of judgment-making. In addition, they don't simply define a fallacy as any error in reasoning, but instead call them "argument patterns" where the probative value of the reasoning in question is less than the rhetorical effect (p. 63). Defining fallacy in this way is not immune to criticism, ${ }^{10}$ but it does have the benefit of pointing out the idea that fallacious reasoning often appears to be convincing, when there are good evidential reasons to reject it as being so. Furthermore, Bailin and Battersby's treatment of fallacies is nuanced in that they underscore the problem of labeling a piece of reasoning as fallacious in the practice of dialogue (pp. 205-208). It is never enough from their perspective to label a fallacy without justifying why the fallacy is so labeled. Furthermore, in social contexts, the label can actually distract from the substance of the critique, so in practice, readers are discouraged from labeling at all, and instead are prompted to explain what about a pattern of argument is problematic, and suggest ways it could be improved (pp. 205-208). For these reasons their treatment of fallacies is superior to many other approaches.

Another major boon of Bailin and Battersby's textbook is that it explicitly addresses critical thinking dispositions, or what they call the "spirit of inquiry". ${ }^{11}$ On their view, fallacious arguments are often a failure of the spirit of inquiry, so that exhibiting closed-mindedness, a lack of fair-mindedness, and other cognitive biases such as groupthink, ideological fixity, and the desire to be correct often lead to fallacious patterns of thought.

While referring to the spirit of inquiry early in their book (pp. 14-15), they also dedicate an entire chapter to exploring what this means for students who are trying to be better critical thinkers (pp. 192-210). Readers are thus reminded that their attitudes matter, and that to be a critical thinker it is never enough to be a negative criticizer, a ruthless fallacy-finder, focused exclusively on winning arguments or gainsaying other perspectives. Instead, readers are encouraged to take a positive and respectful approach to thinking about alternative perspectives, with a view not just to knock them down, but to see how they illuminate our judgment. This is instrumental in fostering critical thinking skills in our students, helping them to become better critical thinkers: people who are both willing and able to go through a process of careful thinking, being open- and fair-minded of alternatives in their efforts to come to reasoned judgments.

Finally, what distinguishes Bailin and Battersby's book from any other approach I have seen is that a good portion of it is written in dialogue form. Students are exposed to a process of cooperatively examining controversial issues through the exchange of reasons for or against. The book exemplifies real-life conversations that might take place regarding euthanasia, capital punishment, the legalization of marijuana, and polygamy, just to cite a few examples. One critique of this approach is that these dialogues are clearly manufactured and somewhat artificial, and seem to always end up with a politically progressive judgment. However, these problematic aspects are mitigated by the many endnotes to each chapter that point the reader in the direction of relevant materials that explore the issues further. The dialogues thus exemplify real differences of opinions, real reasons, and real sources that inform the real issues in question. Readers have the opportunity to follow up on the issues and use the dialogues as jumping-off platforms for further inquiry. Importantly, this gives students a place to go in their own thoughtful questioning concerning the issues, so that after the book is read and after the class is done, the book can still serve as a substantive resource for exploring further the issues at play, not just as a handbook for looking up techniques of argument analysis, or as a resource for "answers" regarding controversial issues.

The text does have drawbacks, such as a problematic definition of deductive arguments as those in which "it appears that the author intended the truth of the premises to guarantee the truth of the conclusion" (p. 45), (cf. Fohr, 1980). Such shortcomings notwithstanding, this book offers a refreshing and informed take on what critical thinking means, and what it means to teach it and pursue it as a learner. It is written by scholars in the field, it avoids many traps of a traditional presentation of fallacies, and it stresses attitudes and dispositions and the process of dialectical inquiry. Finally, it avoids the mistake of simply equating critical

\footnotetext{
${ }^{10}$ E.g. Finocchiaro (1981), who would gainsay this definition with the claim that fallacies, if they are defined as a common pattern of reasoning, are non-existent, in that they are not in fact found commonly in actual discourse.

${ }^{11}$ Bailin and Battersby follow Glaser (1941, p. 10) in referring to the "spirit of inquiry"; Cf. "the critical spirit" of Siegel and Passmore, mentioned above.
} 
thinking and argument analysis. For all of these reasons it is a more attractive textbook than many on the market today (Cf. two reviews of Bailin and Battersby's textbook: Carroza, 2012 and Blair, 2012).

\section{Conclusion}

Because of the proliferation of textbook choices that do not reflect an awareness of current informal logic and critical thinking scholarship, I call on authors of critical thinking textbooks to revise their books accordingly, so that those treatments do reflect an awareness of such scholarship. More importantly, though, I appeal to critical thinking instructors to familiarize themselves with the relevant literature before adopting a textbook and designing and teaching a course in critical thinking. If a textbook does not reflect a familiarity with that literature, it should not be adopted. In this way the over-abundance of less-than-ideal critical thinking textbooks will be mitigated by a more informed and discriminating customer base. While I have only examined two textbooks according to what I take to be important (but not exhaustive) criteria, informed by important debates among theorists, I nevertheless hope I have indicated how instructors might go about examining other textbooks in an analogous fashion. If they do, I think they will find many textbooks lacking, and will gravitate towards better choices.

\section{Acknowledgements}

The Association for Informal Logic and Critical Thinking (AILACT) awarded an earlier version of this paper its 2012 Essay Prize. I would like to express my thanks to AILACT and to the jury members of the 2012 AILACT Essay Prize for their recognition. I would also like to thank Cate Hundleby, as well the editors and reviewers of Paideusis, for their helpful comments and suggestions.

\section{References}

Bailin, S., Case, R., Coombs, J., Daniels, L. (1999a). Common misconceptions of critical thinking. Journal of Curriculum Studies, 31(3), 269-283.

Bailin, S., Case, R., Coombs, J., Daniels, L. (1999b). Conceptualizing critical thinking. Journal of Curriculum Studies, 31(3), 285-302.

Bailin, S., \& Battersby, M. (2010). Reason in the balance: An inquiry approach to critical thinking. Canada: McGrawHill Ryerson.

Battaly, H. (2006). Teaching intellectual virtues: Applying virtue epistemology in the classroom. Teaching Philosophy, 29(3), 191-222.

Battaly, H. (2007). Attacking character: Ad hominem argument and virtue epistemology. Informal Logic, 30(4), 361-390.

Blair, J.A. (2006). Informal logic's influence on philosophy instruction. Informal Logic, 26(3), 259-286.

Blair, J.A. (2012). Book review: Reason in the balance by Sharon Bailin and Mark Battersby. Informal Logic, 32(4), 454-466.

Carroza, L. (2012). Review of Reason in the balance: An inquiry approach to critical thinking by Sharon Bailin and Mark Battersby. Inquiry: Critical Thinking Across the Disciplines, 27(1), 47-49.

Dewey, J. (1910). How we think. Mineola: Dover.

Ennis, R.H. (1989). Critical thinking and subject specificity. clarification and needed research. Educational Researcher, 18(3), 4-10.

Ennis, R.H. (1996). Critical thinking dispositions: Their nature and assessability. Informal Logic, 18, 165-182.

Facione, P. (1990). Critical thinking: A statement of expert consensus for purposes of educational assessment and instruction. Millbrae, CA: The California Academic Press.

Facione, P. (2000). The disposition toward critical thinking: Its character, measurement, and relationship to critical thinking skill." Informal Logic, 20(1), 61-84. 
Finnochiaro, M. (1981). Fallacies and the evaluation of reasoning. American Philosophical Quarterly, 18, 13-22.

Fohr, S.D. (1980). The deductive-inductive distinction. Informal Logic Newsletter, 2(2), 5-8.

Glaser, E. (1941, reprint). An experiment in the development of critical thinking. New York: AMS Press

Govier, T. (1987). Problems in argument analysis and evaluation. Dordrecht: Foris.

Govier, T. (1989). Critical thinking as argument analysis? Argumentation, 3(2), 115-126.

Govier, T. (1995). Reply to Massey. In H. Hansen and R. Pinto (Eds). Fallacies: Classical and contemporary readings. University Park, PA: Pennsylvania State Press.

Govier, T. (2013). A practical study of argument. (Enhanced 7th ed.). Boston: Wadsworth

Hitchcock, D. (2007). Is there an argumentum ad hominem fallacy? In H. Hansen and R. Pinto (Eds.) Reason reclaimed. pp. 187-199. Newport News: Vale Press.

Hundleby, C.E. (2010). The authority of the fallacies approach to argument evaluation.” Informal Logic, 30(3), 279-308.

Johnson, R. (1996). The rise of informal logic. Newport News: Vale Press.

Johnson, R., \& Blair, J. A., (2009). Teaching the dog's breakfast: Some dangers and how to deal with them. AP A Newsletters: Newsletter on teaching philosophy, 9(1), 2-5.

Millman, A.B. (1988). Critical thinking attitudes: A framework for the issues." Informal Logic, 10(1), 45-50.

Missimer, C. (1990). Perhaps by skill alone. Informal Logic, 12, 145-153.

Missimer, C. (1995). Where's the evidence? Inquiry: Critical Thinking Across the Disciplines, 14, 1-18.

Munson, R., \& Black, A. (2012). The elements of reasoning (6 $6^{\text {th }}$ ed.). Belmont: Thompson.

Passmore, J. (1967). On teaching to be critical. In R. S. Peters, (Ed.), The concept of education. pp. 192-212.

London: Routlege \& Kegan Paul.

Publisher's Comments (n.d.). Accessed June 2, 2013, at

http://www.powells.com/biblio?show=TRADEPAPER:NEW:9780495809180:75.80\#synopses_and_review $\underline{\mathrm{s}}$

Scheffler, I. (1986). Inquiries: Philosophical studies of language, science and learning. Indianapolis: Hackett.

Siegel, H. (1988). Educating reason. London: Routledge

Weinstein, M. (1995). Critical thinking: Expanding the paradigm. Inquiry: Critical thinking across the Disciplines, 15, 1, 23-39.

\section{About the Author}

Benjamin Hamby is a doctoral candidate (ABD) in Philosophy at McMaster University, Hamilton, Ontario, Canada. His thesis concerns the connection between critical thinking skills and virtues. He can be reached at hambyb@mcmaster.ca 